\title{
E-Learning And Instructional Management System Based On Local Computer Networks And Internet
}

\author{
Hasan F. Khazaal, Wasit University, Iraq \\ Riyadh A. Abbas, Wasit University, Iraq \\ Basim M. Abdulridha, Wasit University, Iraq \\ Marc Karam, Tuskegee University, USA \\ Heshmat Aglan, Tuskegee University, USA
}

\begin{abstract}
This article describes the educational efforts invested at Wasit University (WU), in Wasit, Iraq, in order to make WU the first university in that country to implement campus-wide e-learning, which is essential for any country aiming for progress through the essential goal of "Education For All"; e-learning being economic, far-reaching, and relatively simple to implement. These efforts have materialized in an integral e-system that performs and manages a complete educational process that can be used by any educational organization (schools, colleges, or continuing education centers) in a highly flexible, reliable, and secure manner. The e-learning management system architecture consists of three layers: user's interface layer, middle layer, and server layer. The user interface layer is composed of four modules: user interface module, teacher module, student module, and administrator module. Each module has several sub-modules that are described in detail throughout the paper. Our proposed e-learning system has been successfully tested on some courses in the Electrical Engineering Department at WU. Our primary objective is to implement it department-wide, evaluate it, and refine it. Once satisfactory and efficient, the goal is to expand its use throughout WU, and eventually to all other institutions of learning in Iraq.
\end{abstract}

Keywords: E-Learning; User Interface Layer; Teacher Module; Student Module; Administrator Module

\section{INTRODUCTION}

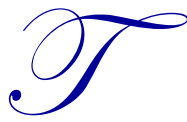

he emergence of advanced software and hardware technology bridges the needs of educational institutions to develop new trends in educational technology through investing in computer network facilities and their connections with the World Wide Web. New educational means and methodologies have been developed using these technologies with the aim of improving the effectiveness of education. Electronic learning (e-learning) is one of the educational methods that was created in order to maintain high teaching levels through the use of computer programs and systems. E-learning helps teachers to present educational topics using two options: face to face learning via Ethernet inside classrooms and laboratories, or distance learning via wired or wireless local area networks (LANs) or wide area networks (WANs). The use of computers throughout the teaching process enables teachers to control the flow of the learning process by providing the flexibility to explain and re-explain the curriculum content in a time-efficient manner and discuss the presented topics with the students and receive their feedback. Furthermore, it enables them to control the examinations and store the results in a flexible manner that allows editing and deleting unsatisfactory ones. As far as students are concerned, e-learning offers a significant service. They can access the topics anytime anywhere by accessing the Web (distance learning), as well as entering the classroom to get lessons and notes from the teacher directly (open learning). In addition, distance learning allows students with disabilities who have trouble accessing the classroom and students maintaining jobs during the day, who need to work on classes when it is convenient for them, the convenience of having content delivered to their location on their schedule. Moreover, students have the ability to 
discuss subjects freely with their teachers. Last but not least, an environmental advantage of e-learning is that it reduces waste in paper usage.

Unfortunately, in Iraq, e-learning is used neither in education or industry, nor throughout research and development centers, in contrast to many other countries where it is used at least in continuing education and in research and development centers. In response, the College of Engineering at Wasit University (WU) in Wasit, Iraq, proposes to be the first institution of higher learning in Iraq to implement an e-learning system, which would be a model for other Iraqi universities and educational institutions.

\section{RELATED WORK}

Recently, several teaching institutions and continuing education and research and development centers have moved towards e-learning in order to save time and money, and in order to effectively realize their long-sought goal that teaching be available for anyone, anywhere and at anytime. However, as in every new endeavor, challenges have arisen that have prompted several research projects in the development of e-learning. An adaptive instructional system based on the expertise of the user was presented by Pecheanu, Segal, and Dumitriu (2011). E-learning instructional platforms of the campus networks of Hebei University and North China Electric Power University in China are described by Zhang and Wang (2010). These platforms can be accessed anywhere by using personal computer terminals that are connected to the campus networks. A robust framework design for online systems engineering education was introduced by Squires and Cloutier (2011). The design thrust of this framework was to identify an approach for optimizing students' learning experience and gaining competency knowledge in systems engineering. The obstacles that face the spread of e-learning in Croatian universities were discussed by Puvaca, Roso, and Zdrilic (2010). A design for blended education methods, introduced to make the instruction process more satisfactory, has been outlined by Cheung, Lam, Lau, and Shim (2010).

An e-learning system architecture for employees' education in the manufacturing industry has been proposed by Xin (2009) to incorporate the functions of manufacturing training materials, scenario case base, and database in terms of integrating web-based and collaborative problem solving methods. An educational program tool intended to increase the feedback received from students during interactive synchronous teaching sessions was introduced by Soreanuand and Saucan (2003). The program worked in a semi-continuous, nonobtrusive way, giving information about predefined parameters. Another framework that makes comparisons between traditional learning and e-learning has been proposed by Murillo and Velázquez (2008). This was in order to prove that the latter is better than the former as far as "learning for all" is concerned.

An online course quality evaluation using thirteen sub-criteria measurements based on four dimensions: course content, instructional design, service design, and system support, to examine online course quality was discussed by Jie (2010). This study gave an example of how to solve multiple-attribute decision-making problems using a fuzzy analytical hierarchy process. It developed a fuzzy evaluation model that prioritizes the relative weights of online course quality factors.

In this paper we introduce a novel e-learning framework to develop the instruction process for the entire education system at WU, Iraq. The proposed system includes an adaptive educational management component and a structure for archiving the entire body of events of the learning process within the entire academic year.

\section{E-LEARNING SYSTEM ARCHITECTURE}

The proposed e-learning system architecture and algorithm are shown in Figures 1 and 2. It is composed of the following three layers: users' interface layer, middle layer, and server layer. Each of these layers is described below. 


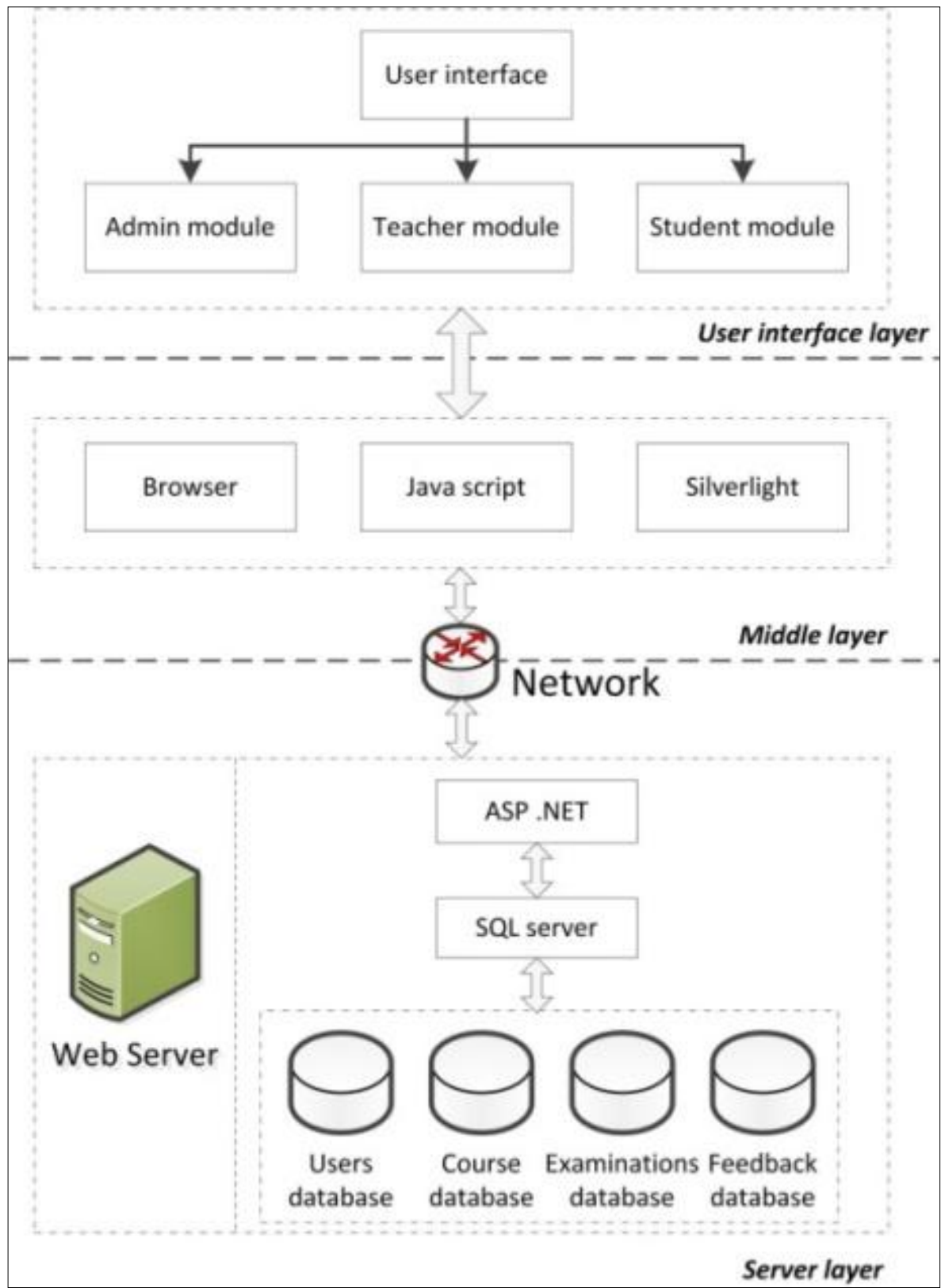

Figure 1: E-learning with Management System Architecture 


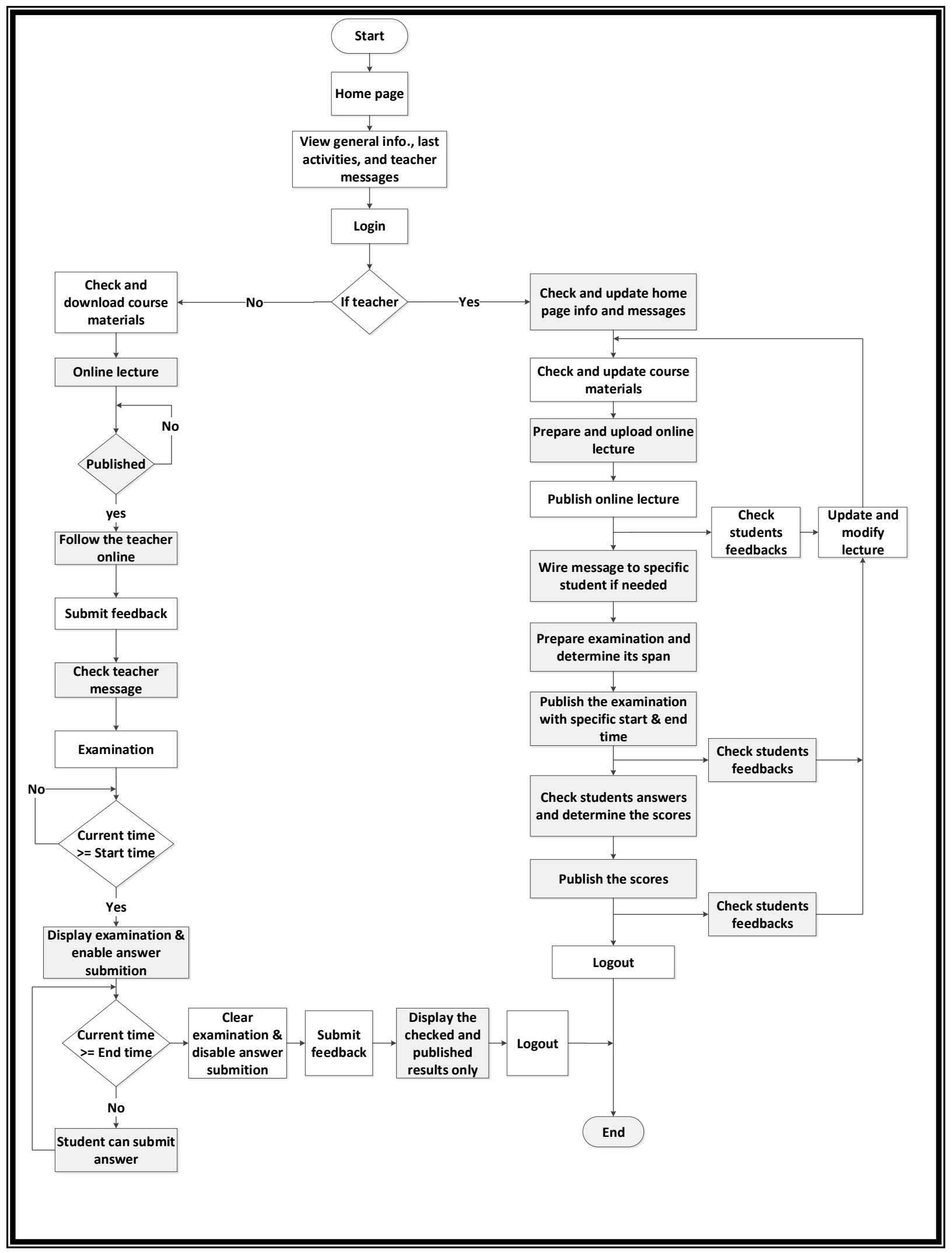

Figure 2: E-Learning System Algorithm 


\subsection{User Interface Layer}

This layer represents the environment of communication between the users themselves and between the users and the whole system layers. There are four modules within this layer, namely: the user interface module, the student module, the teacher module, and the administration module. Each of the modules contains sub-modules, and each sub-module has a specific task as described next.

\subsubsection{User Interface Module}

This module contains the home page and the login sub-modules, both described below.

\subsubsection{Home Page Sub-Module}

In this module a given course is announced with a brief description, along with the teacher's messages and the last activities of the department and college as shown in Figure 3.

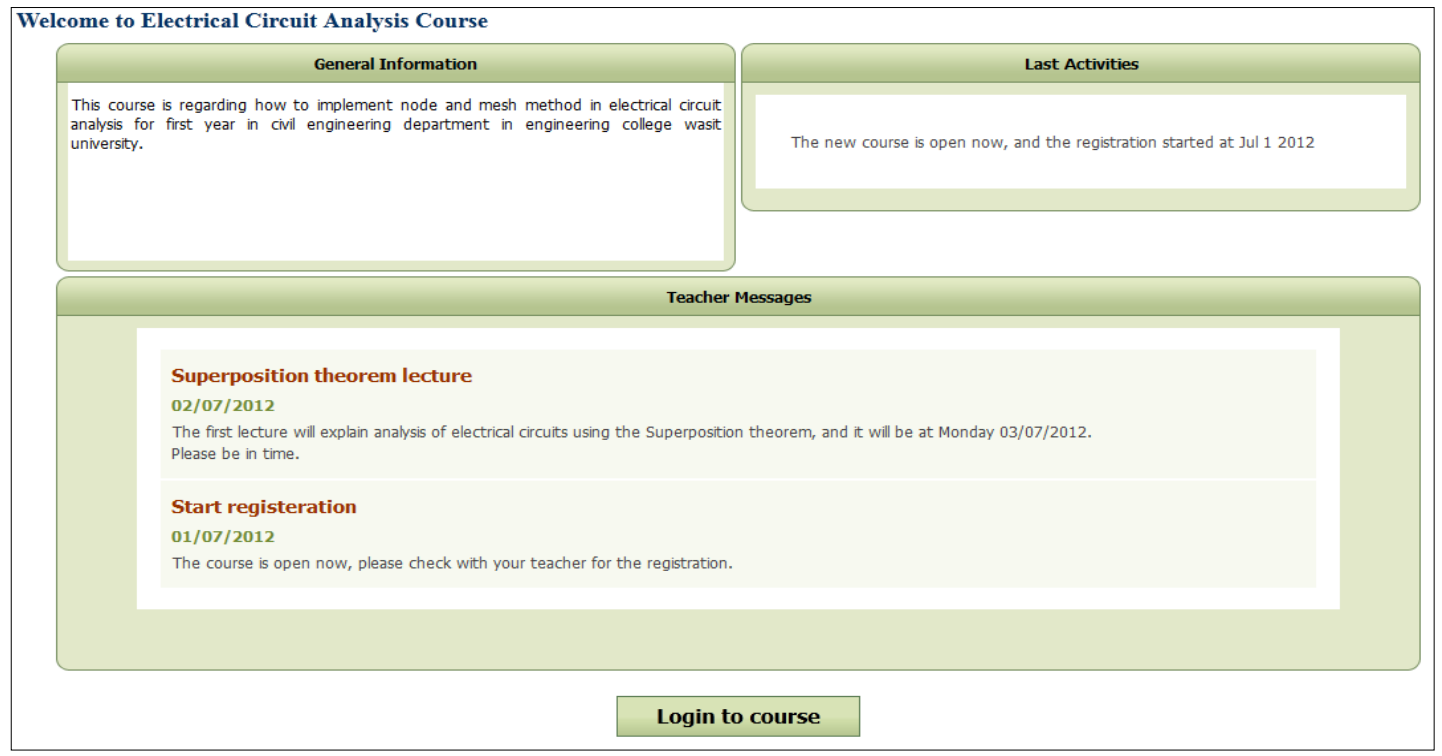

Figure 3: Home Page Sub-Module

\subsubsection{Login Sub-Module}

This module is used to login to the courses or any activities that are announced on the Home Page and it is accessible by authorized users who have an ID and a password as shown in Figure 4.

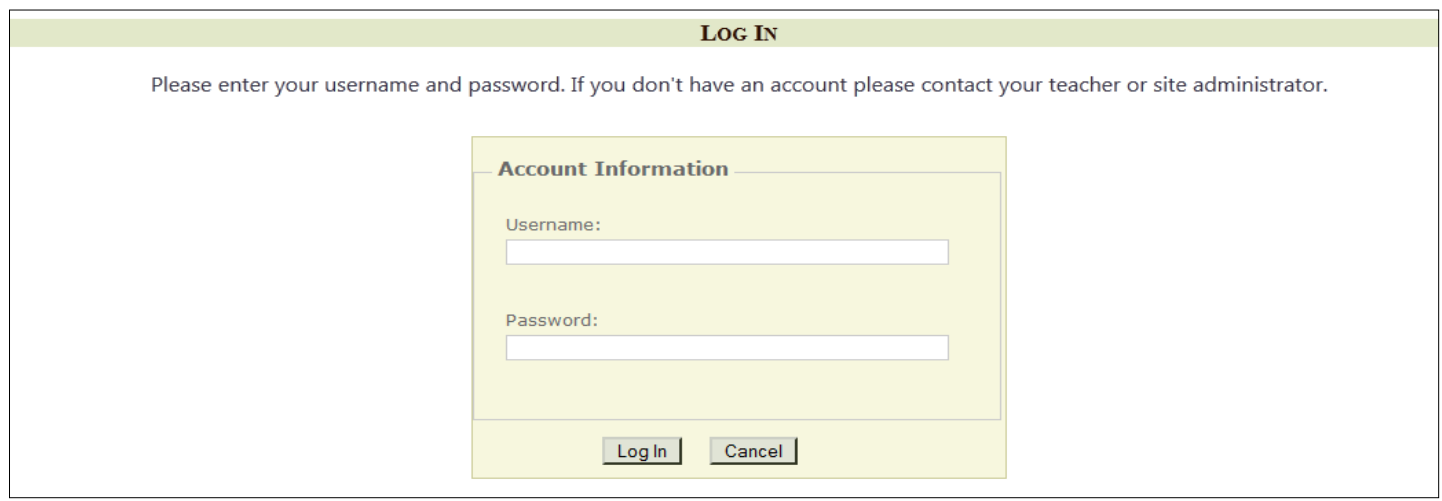

Figure 4: Login Sub-Module 


\subsubsection{Teacher Module}

This module contains 16 sub-modules available only to teachers. Each of these sub-modules is described below.

\subsubsection{Teacher's Main Page Sub-Module}

In this sub-module the teacher can announce general messages and post the last activities in the course as well as notes to the students as shown in Figure 5.

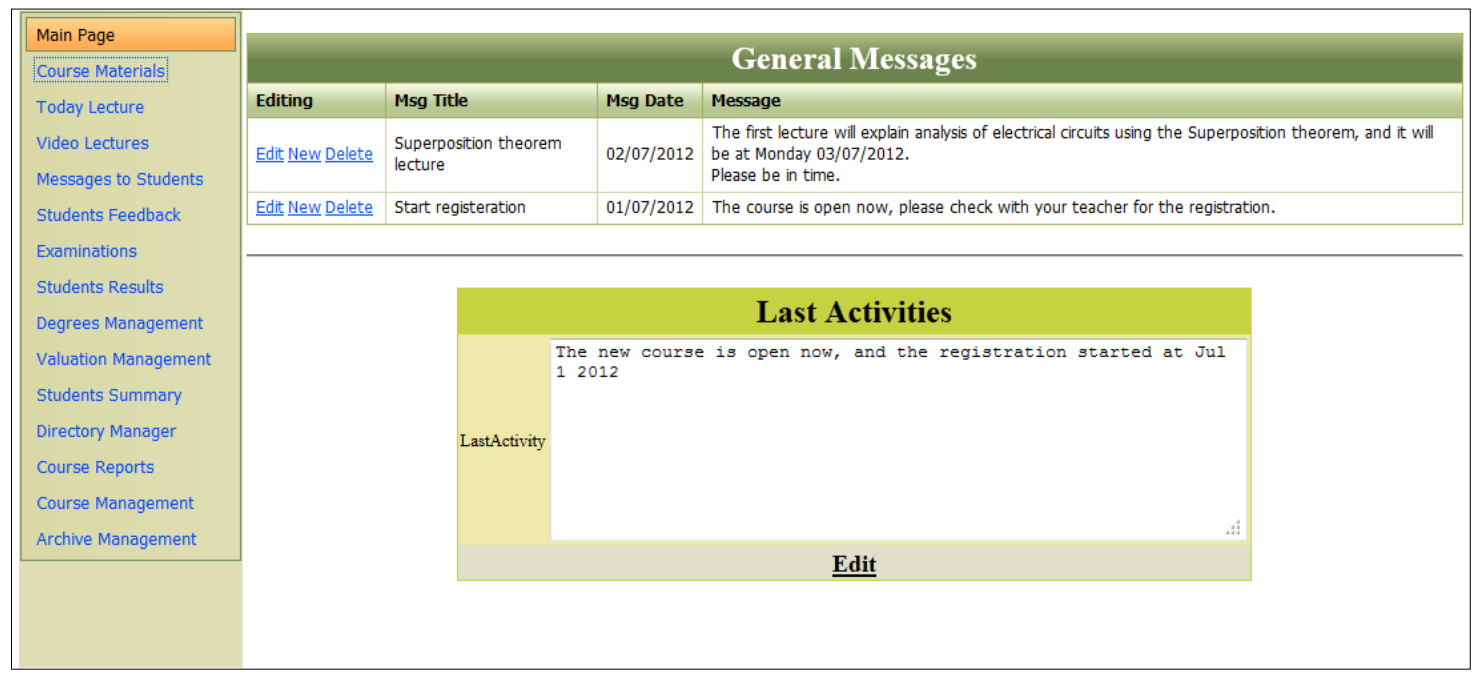

Figure 5: Teacher's Main Page Sub-Module

\subsubsection{Teacher's Course Materials Sub-Module}

The course materials prepared by the teacher are available in this module, as well as the teacher's notes related to the course as shown in Figure 6.

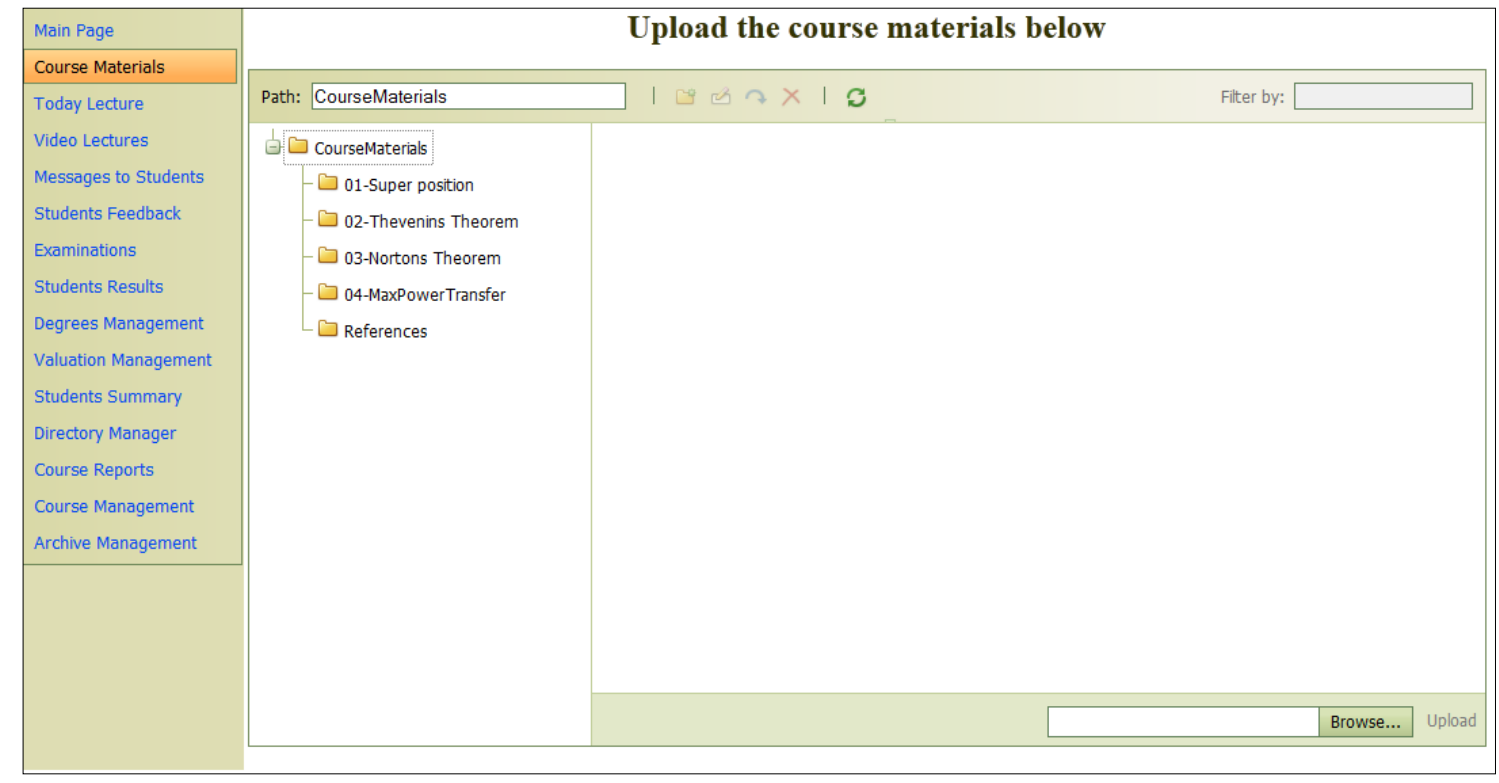

Figure 6: Teacher's Course Materials Sub-Module 


\subsubsection{Teacher's Today Lecture Sub-Module}

This sub-module gives teachers the possibility to post selected lectures in PDF format as shown in Figure 7.

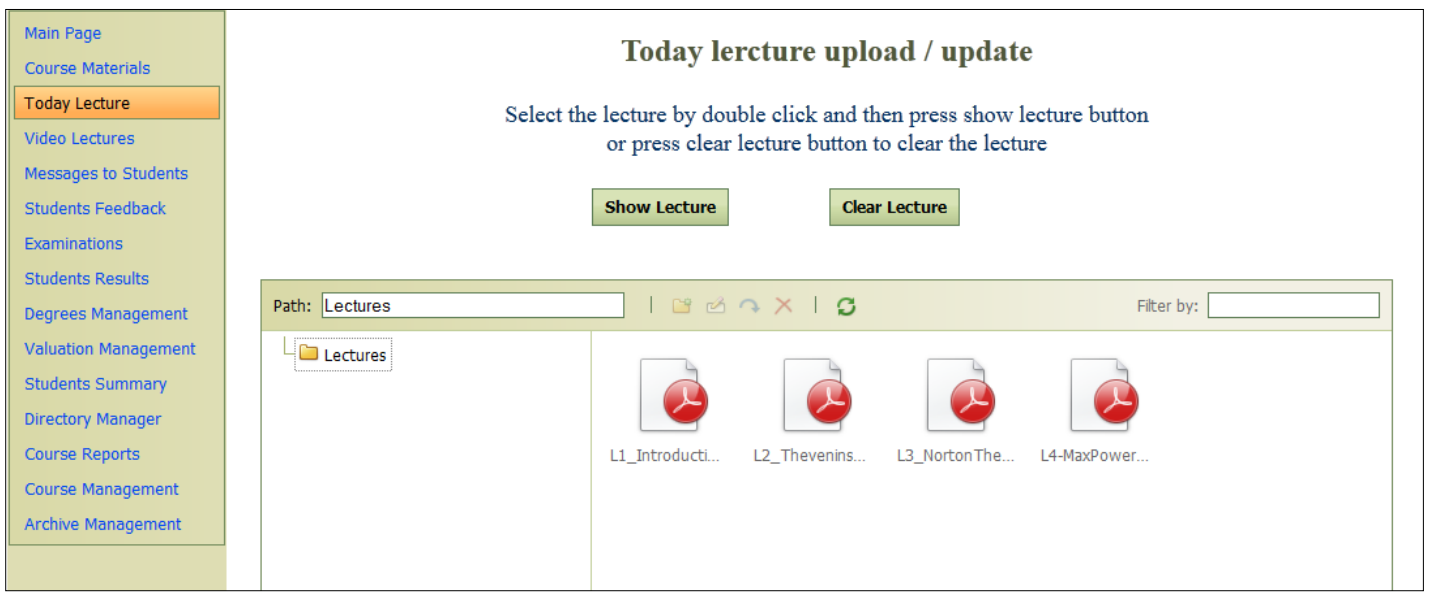

Figure 7: Teacher's Today Lecture Sub-Module

\subsubsection{Teacher's Video Lecture Sub-Module}

Teachers may desire to present part or all of their lectures in video format in order to draw the attention of the students or to reinforce their understanding when using various blended instructional technology methods. For example in an electrical engineering course, videos illustrating circuits, electricity, Ohm's Law and resistance may be made available.

\subsubsection{Teacher's Messages to Students Sub-Module}

The teacher's various messages to each student or to all of them are managed through this sub-module. The teacher can write messages that do not exceed 500 characters and select from the list of students those to whom to send it. This sub-module gives a teacher the ability to send a variety of messages to different students simultaneously as shown in Figure 8.

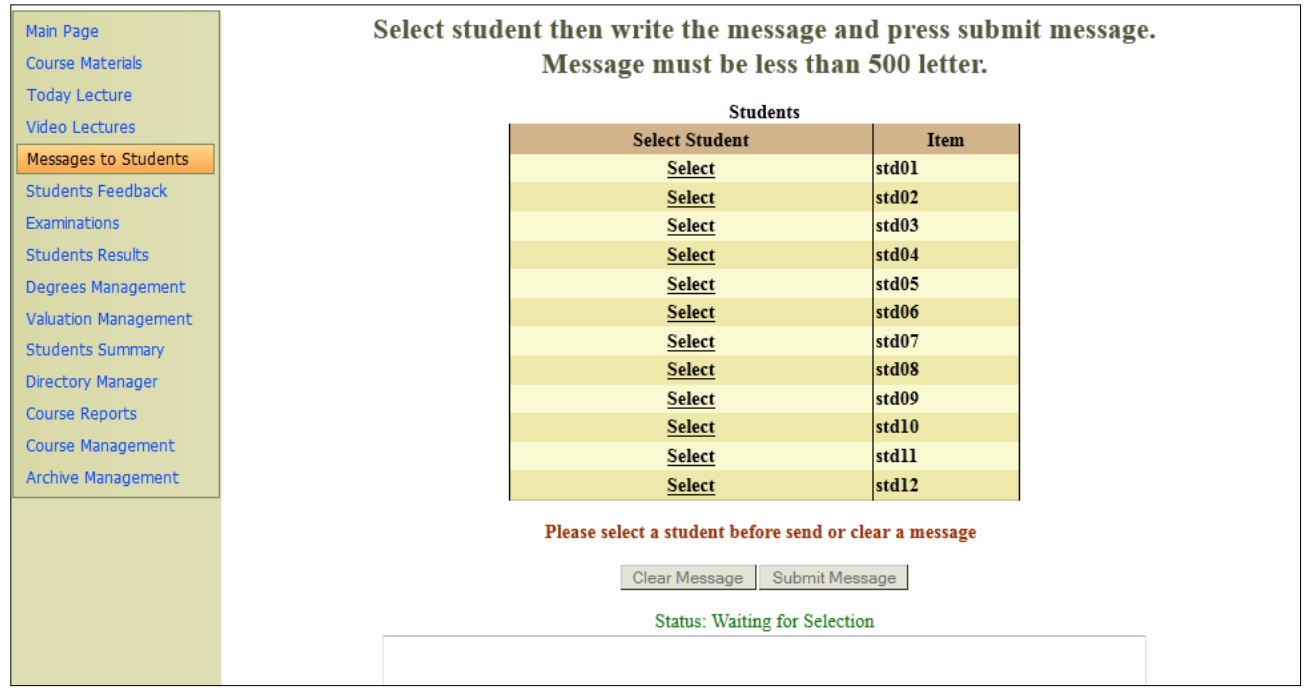

Figure 8: Teacher's Messages to Students Sub-Module 


\subsubsection{Teacher's Student Feedback Sub-Module}

Feedback messages from students to teachers are managed in this sub-module. Each feedback comment is preceded by the name and ID of the student who wrote it as shown in Figure 9.

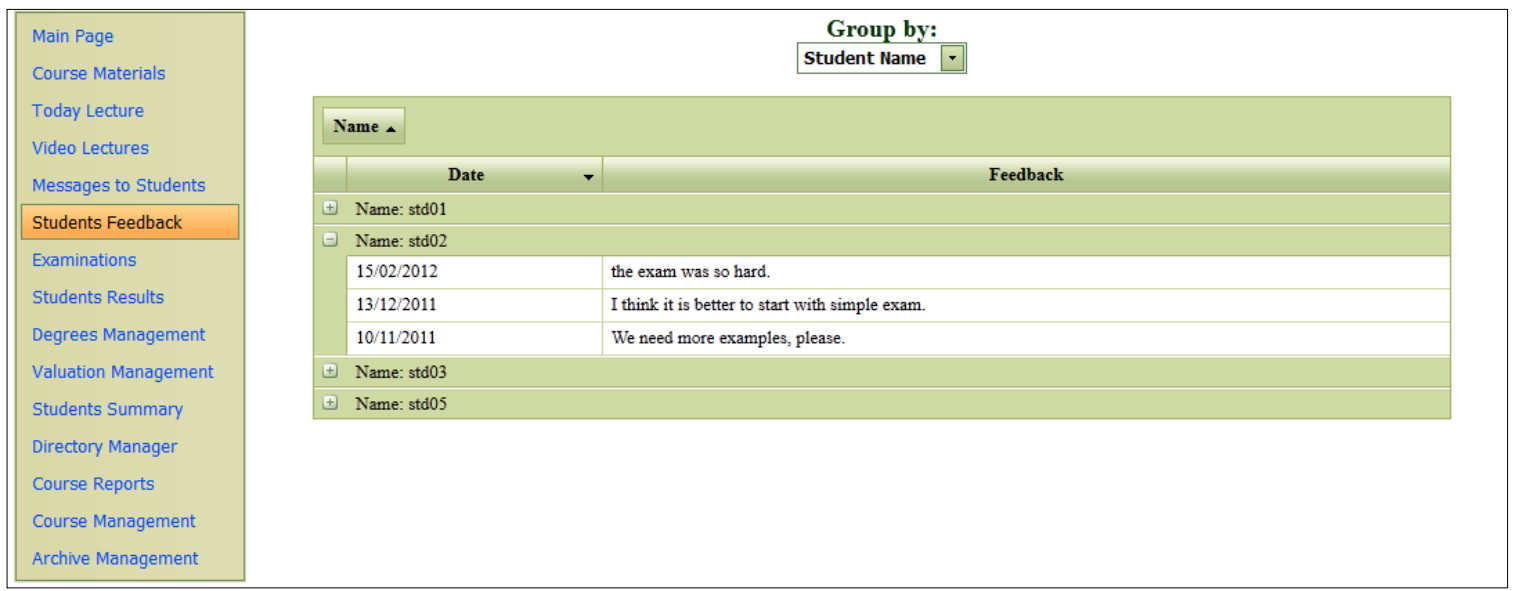

Figure 9: Teacher's Student Feedback Sub-Module

\subsubsection{Teacher's Examination Sub-Module}

By means of this sub-module teachers can administer all kinds of assessments to students (i.e., quizzes, tests, midterm exams, and final examinations). This sub-module offers teachers the possibility to specify and control the amount of time students are allowed to spend working on an assessment. Moreover, teachers can specify the type of the assessment and the maximum score, as shown in Figure 10.

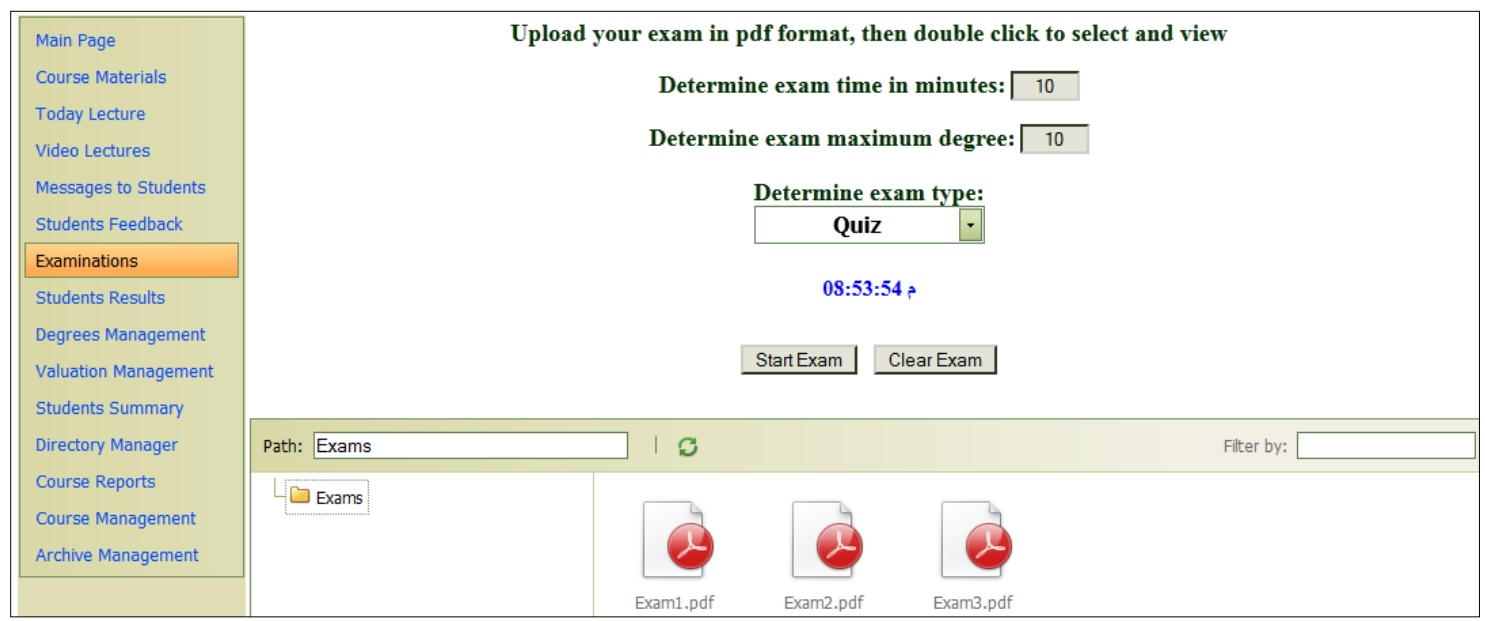

Figure 10: Teacher's Examination Sub-Module

\subsubsection{Teacher's Student Results Sub-Module}

Teachers can use this module to store the scores of various quizzes, tests, and exams for each student and to compute their final grade, as shown in Figure 11. These results are accessible only to teachers so they can evaluate students and manage the instructional process during the academic year. 


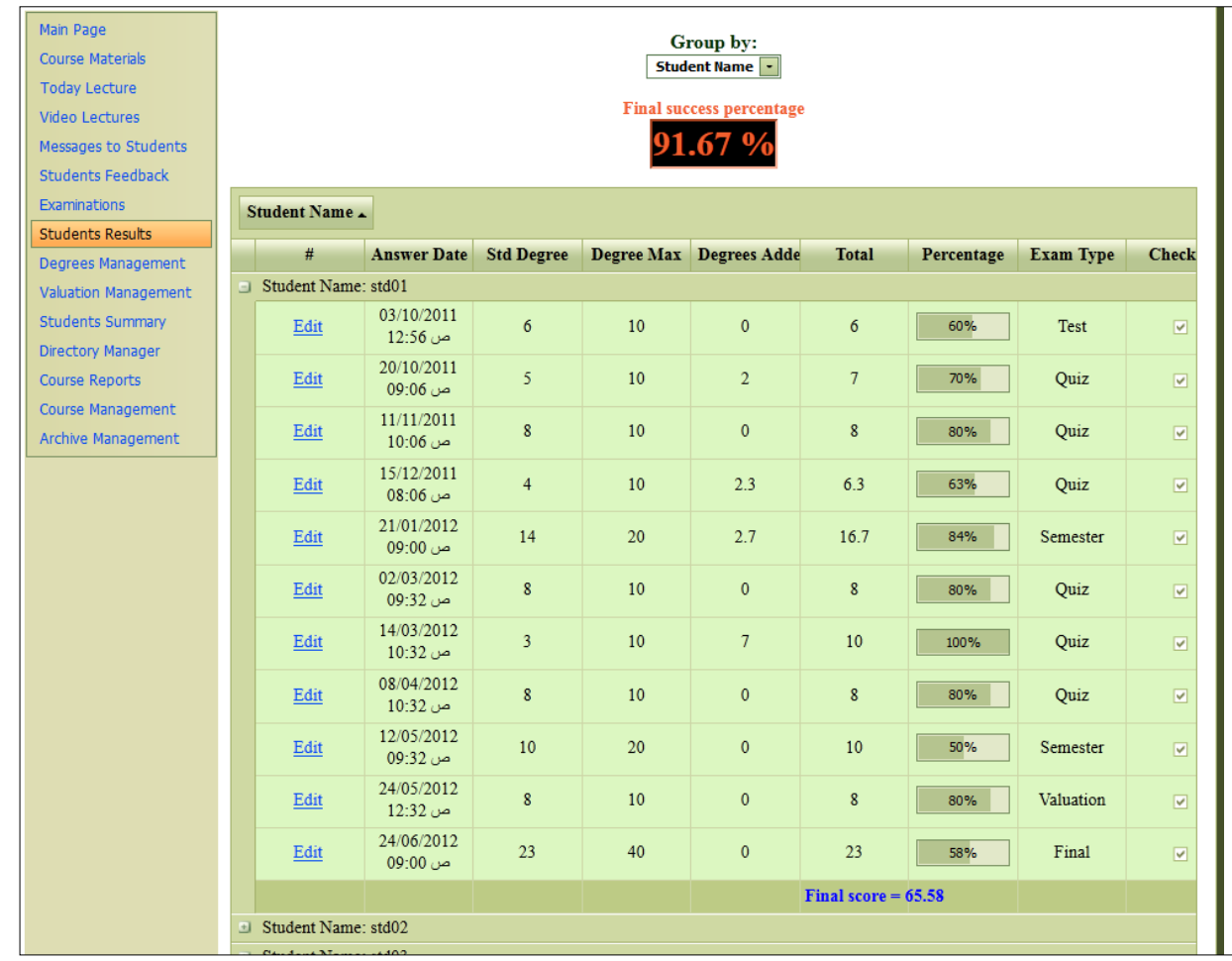

Figure 11: Teacher's Student Results Sub-Module

\subsubsection{Teacher's Grades Management}

Part 1 Sub- Module: With this sub-module, shown in Figure 12, teachers have the ability to manage the scores of students individually or as a group, either by deleting certain examinations or by adding curves, which can be done linearly or nonlinearly. Curving is frequently used in engineering grades. Linear curving involves adding the same number of points to the whole class or to selected students while nonlinear curving uses the formula,

curved grade $=\sqrt{\text { maximum grade }} \times \sqrt{\text { initial grade }}$

The advantage of this formula is that it gives the highest grade of curving to the lowest student grade and vice versa. The decisions and computations related to grade curving are actually performed in the Part 2 sub-module, which is presented in the next sub-section. 


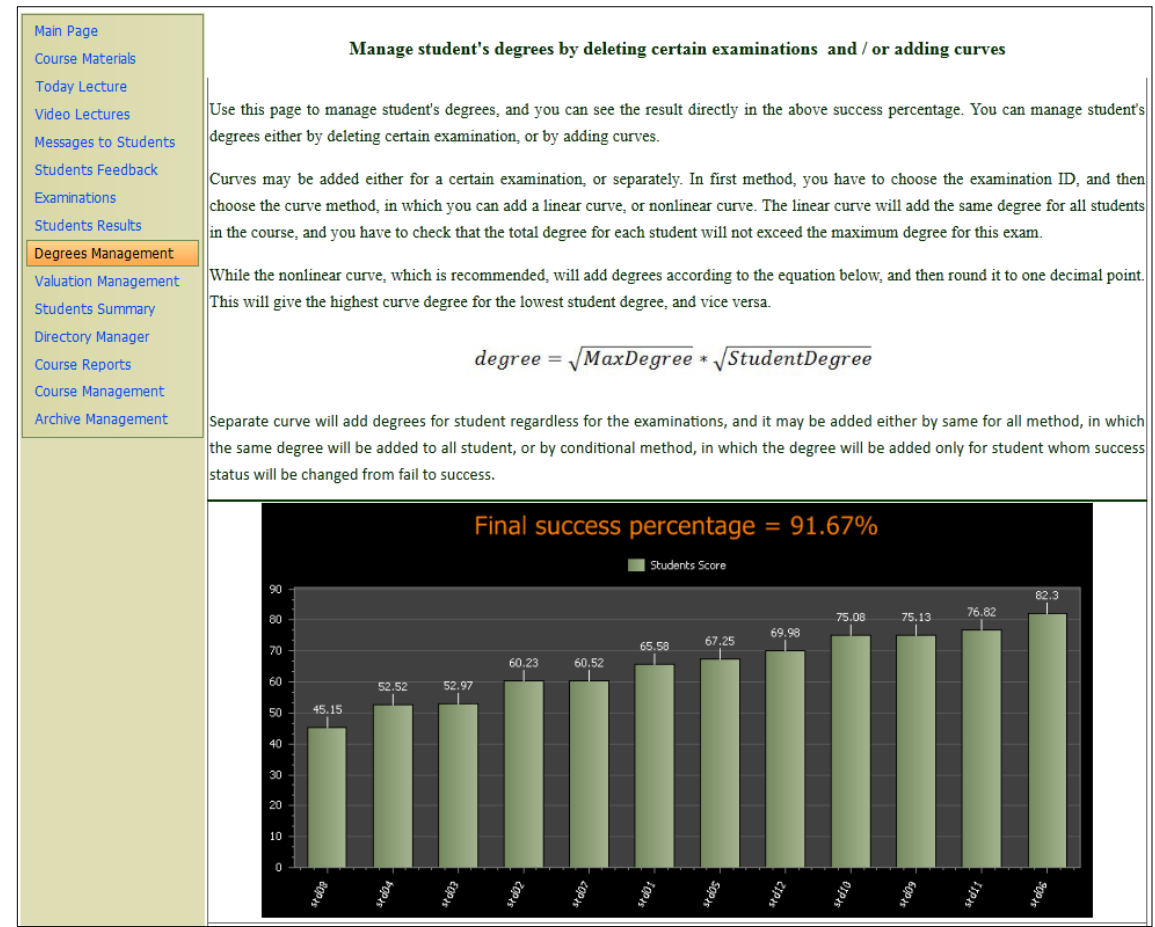

Figure 12: Teacher's Grade Management Part 1 Sub-Module

\subsubsection{Teacher's Grades Management}

Part 2 Sub-Module: This sub-module, shown in Figure 13, is an integral part of the previous sub-module. This is where the management of grade curving is performed in detail for the whole academic year with highly secure documentation and archiving. Teachers have the flexibility to compute one or all students' grades with desired degrees of curving. They can also choose which exams should not be taken into account while computing a student's grade (e.g., if it had been stated in the syllabus that the lowest test or quiz grade would be dropped).

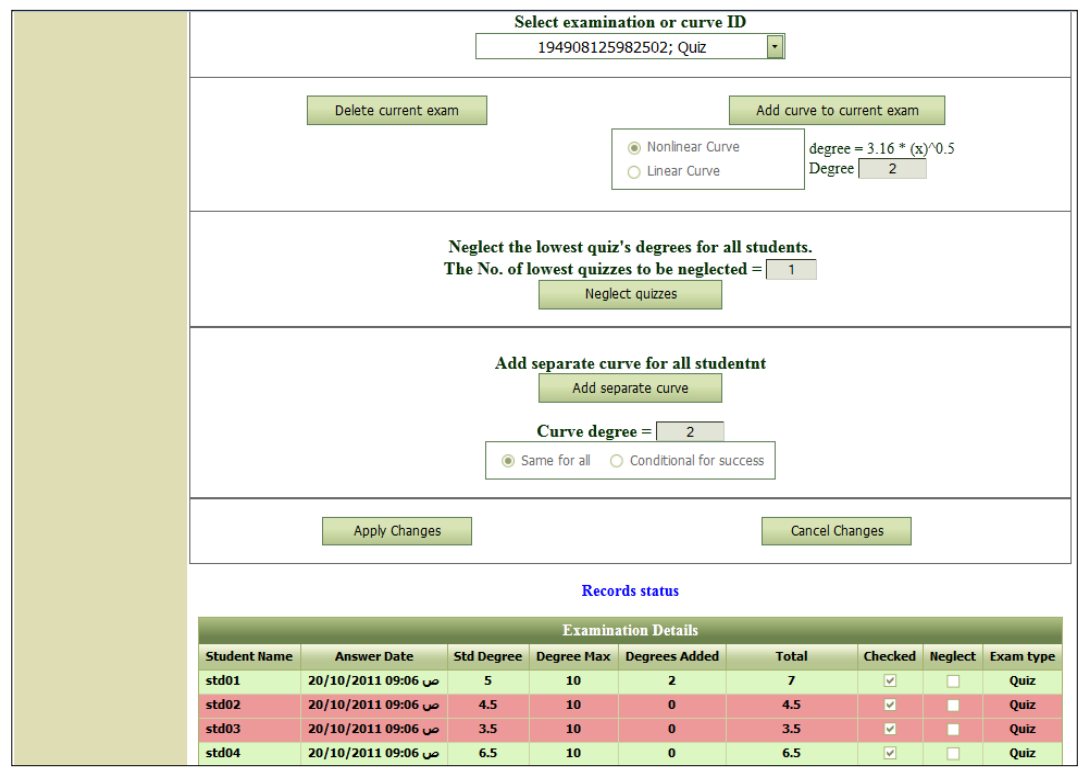

Figure 13: Teacher's Grades Management Part 2 Sub-Module 


\subsubsection{Teacher's Valuation Managements Sub-Module}

Teachers may desire to give extra points, called "valuation points," to students who deserve them for various reasons such as active participation in class or extra problems or points offered on the syllabus. The corresponding sub-module is shown in Figure 14. It gives teachers the ability to add or delete desired valuation points to one or all students. Moreover, teachers can choose the initial and the maximum valuation points they deem fit for a given student. Again, all students would be given the opportunity to gain such points; if such bonus points were made available, this would be stated in the syllabus.

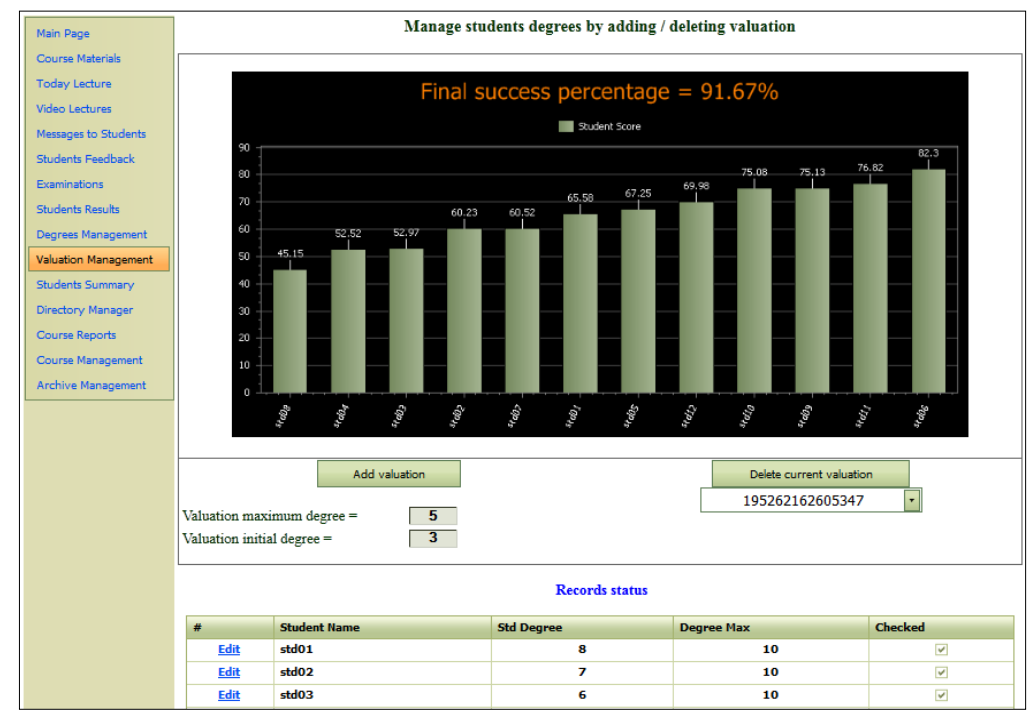

Figure 14: Teacher's Evaluation Management Sub-Module

\subsubsection{Teacher's Student Summary Sub-Module}

This module, shown in Figure 15, gives teachers a global overview of the grades assigned to each student in a course. This includes the number of quizzes, quiz grades, midterm exam grade, valuation points, curving degree, final exam grade, and final score. Moreover, a Pass/Fail indicator for each student is shown on the final success percentage bar graph in form of a green bar for a passing grade and a red bar for a failing grade.

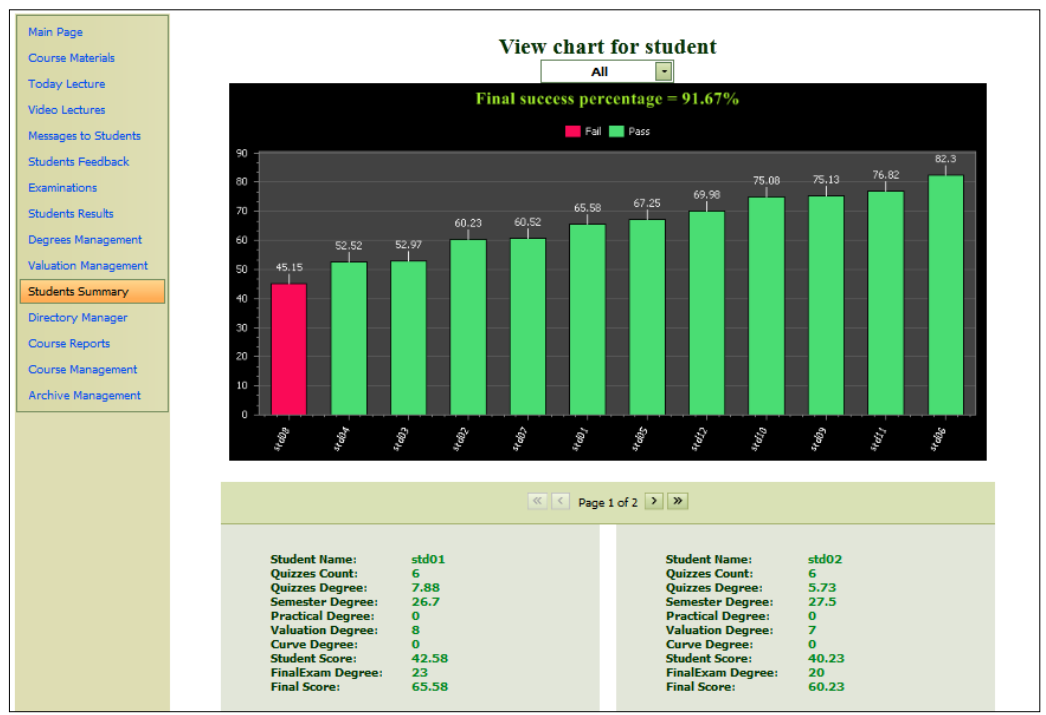

Figure 15: Teacher's Student Summary Sub-Module 


\subsubsection{Teacher's Directory Manager Sub-Module}

This sub-module, shown in Figure 16, allows teachers to manage the tests that their students have submitted online as pdf files.

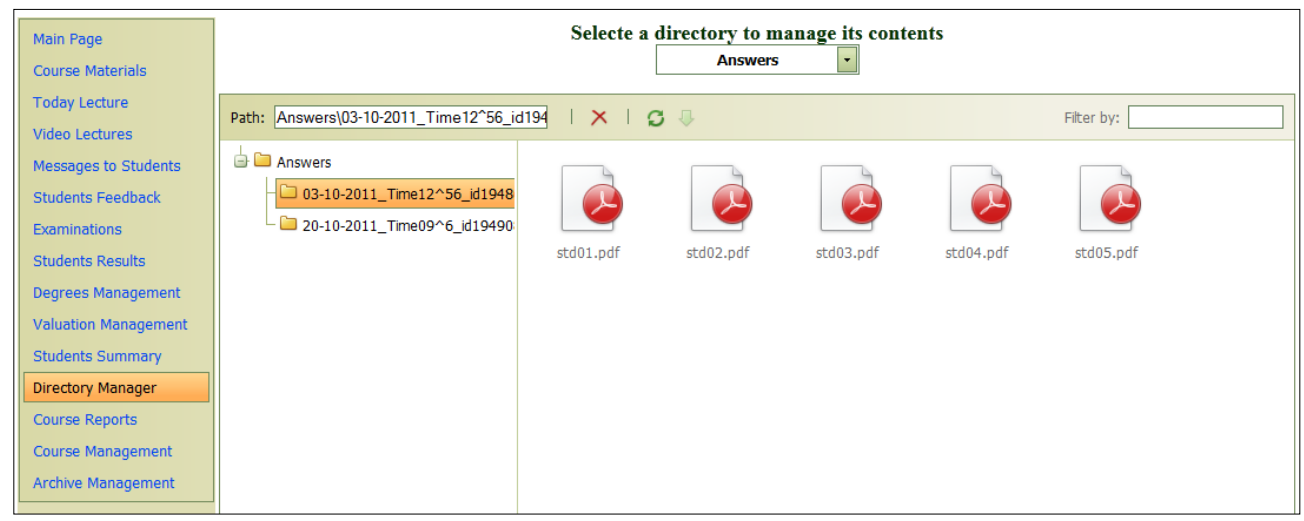

Figure 16: Teacher's Directory Manager Sub-Module

\subsubsection{Teacher's Course Report Sub-Modules}

The teacher's course report has two sub-modules labeled P1 and P2 shown in Figures 17 and 18. Submodule P1 displays a summary of each student's grades in the course as detailed in sub-section 3.1.2.12 above, whereas sub-module P2 gives for each student the date and type of every exam taken in the course, along with the corresponding grade, maximum score, curve grade, and final grade.

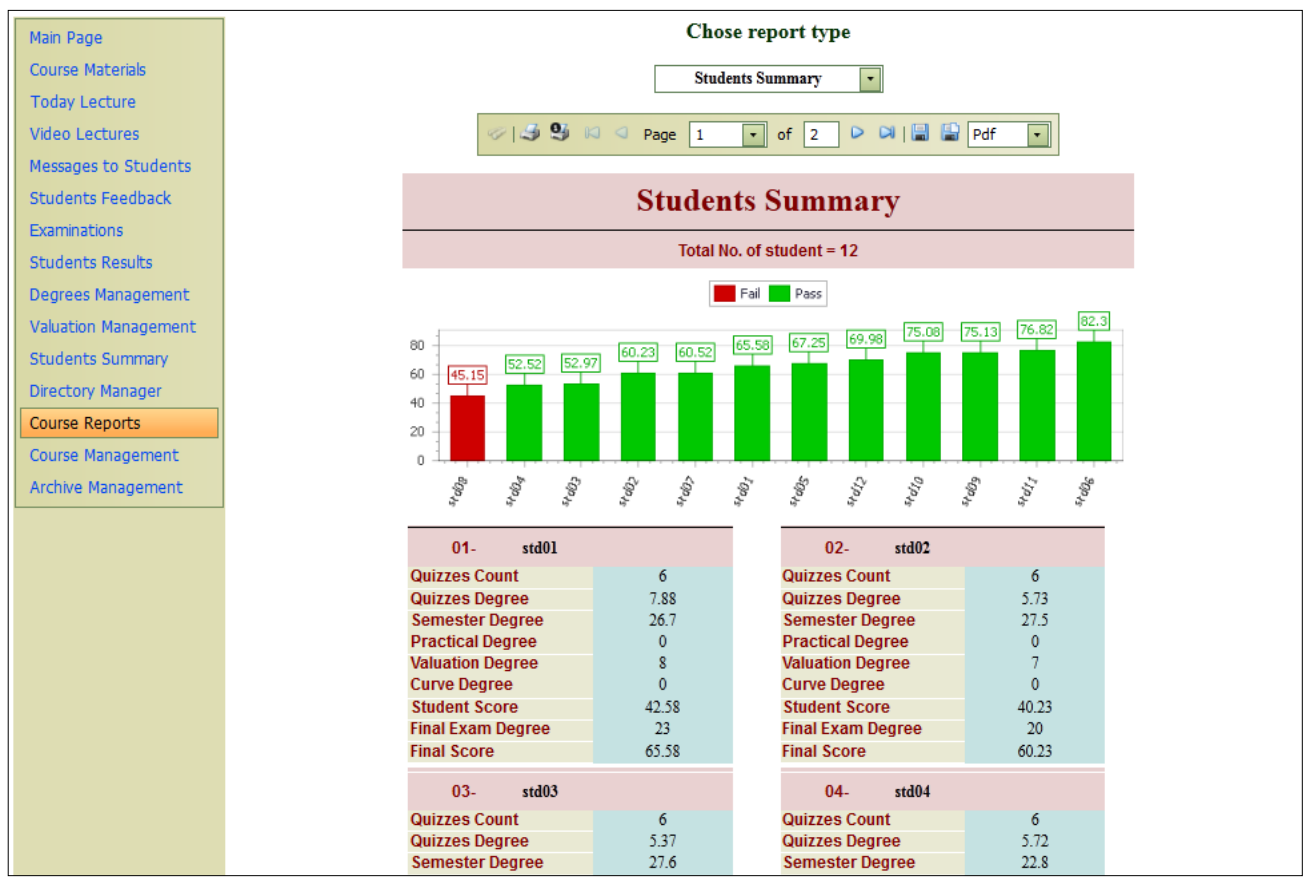

Figure 17: Teacher's Course Report P1 Sub-Module 


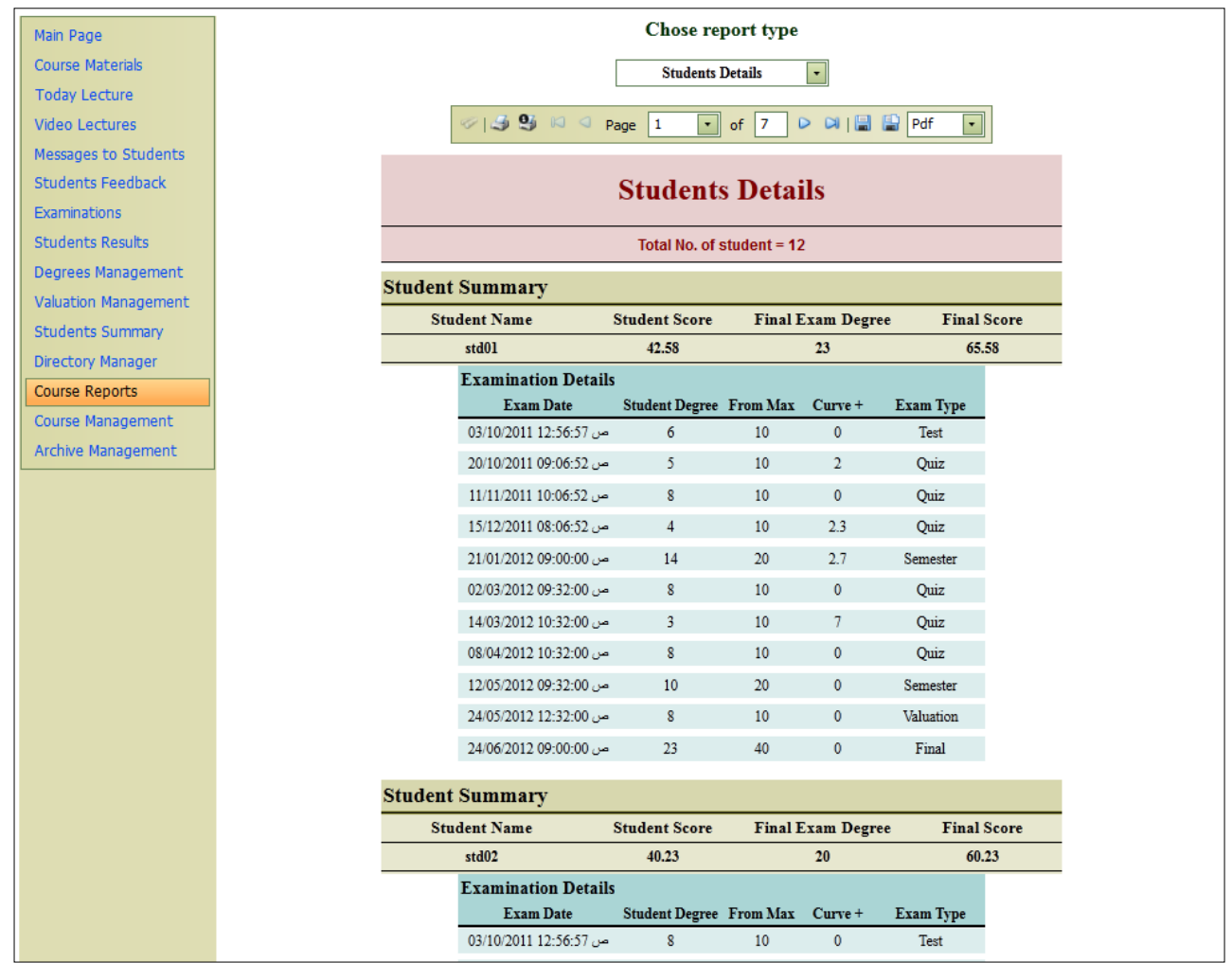

Figure 18: Teacher's Course Report P2 Sub-Module

\subsubsection{Teacher's Course Management Sub-Module}

This sub-module, shown in Figure 19, gives teachers the ability to add or delete selected students' records from a course in case they decide not to take them into account as they compute evaluation results. This module is intended for the instructor's manipulation of grades only, and not for permanent record purposes, and would not follow through to the registrar's office. This would allow the instructor to view for example a class average, only considering students taking the course who are in a specified discipline.

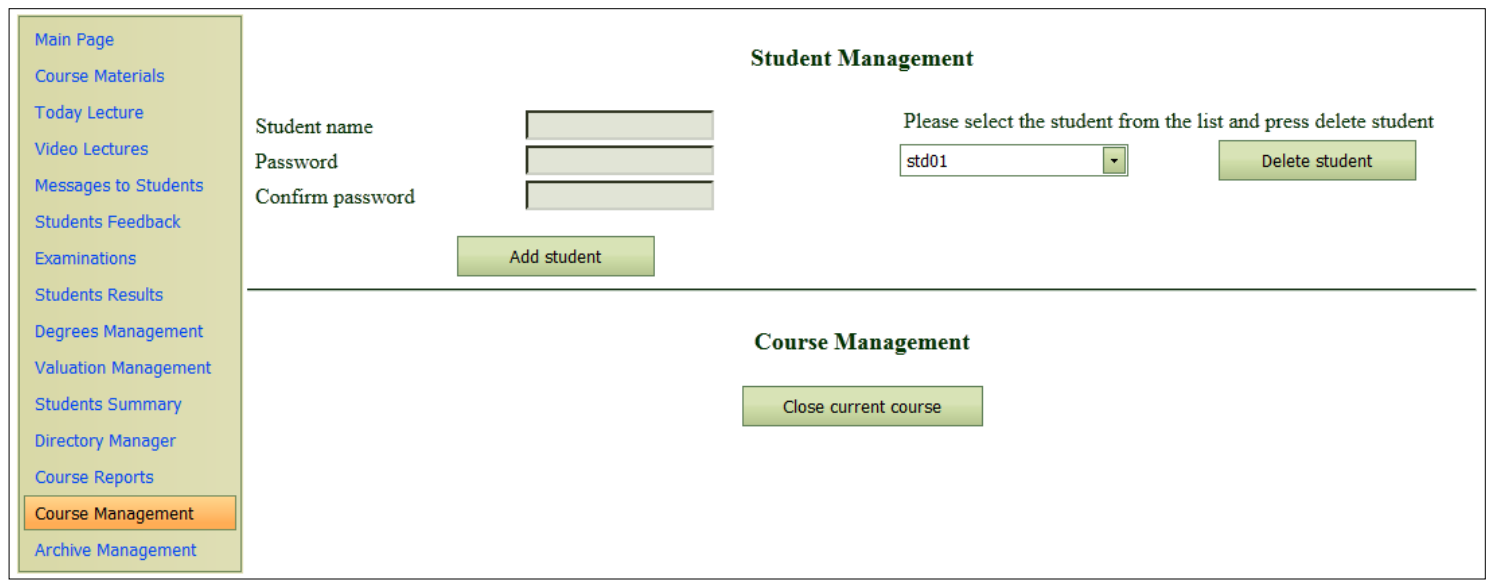

Figure 19: Teacher's Course Management Sub-Module 


\subsubsection{Teacher's Archive Management Sub-Module}

This sub-module gives teachers the capability to archive students' answers on quizzes and exams as well as the corresponding keys and dates administered, along with students' scores and valuation grades as shown in Figure 20.

\subsubsection{Student Module}

This module has several sub-modules that are user-friendly to students and are described in the next subsections.

\begin{tabular}{|c|c|c|c|c|c|c|c|c|c|c|c|c|c|c|}
\hline \multirow{3}{*}{$\begin{array}{l}\text { Main Page } \\
\text { Course Materials } \\
\text { Today Lecture }\end{array}$} & & & & & \multicolumn{3}{|c|}{ Deleted Students } & \multicolumn{7}{|c|}{ Course Archive } \\
\hline & \multirow[b]{2}{*}{ (at } & & & & & & & & & & & & & \\
\hline & & \# & Std Name & \multirow{2}{*}{$\begin{array}{c}\text { Del Date } \\
11 / 08 / 2012\end{array}$} & \multicolumn{2}{|c|}{ Quizzes Count } & \multicolumn{2}{|c|}{ Quizzes Degree } & \multicolumn{3}{|c|}{ Semester Degre€ Practical Degree } & \multicolumn{3}{|c|}{ Valuation Degree Curve Dec } \\
\hline Video Lectures & $\boxminus$ & Edit Delete & Ali & & \multicolumn{2}{|l|}{3} & \multicolumn{2}{|l|}{5} & 22 & \multicolumn{2}{|c|}{0} & \multicolumn{2}{|l|}{9} & 0 \\
\hline Messages to Students & \multicolumn{2}{|r|}{ Exam ID } & Exam Type & Exam Date & Std Degree & Deg & ree Max & \multicolumn{2}{|c|}{ x Degrees Added } & Total Degree & Checked & ad Neglect & \multicolumn{2}{|c|}{ Answer File } \\
\hline Students Feedback & \multicolumn{2}{|r|}{170102723829956} & Quiz & $15 / 07 / 2012$ & 7 & & 10 & & 0 & 7 & $\nabla$ & $\square$ & \multicolumn{2}{|c|}{ View Answer } \\
\hline Examinations & \multicolumn{2}{|r|}{170103590721479} & Quiz & $15 / 07 / 2012$ & 3 & & 10 & & 0 & 3 & $\nabla$ & $\square$ & \multicolumn{2}{|c|}{ View Answer } \\
\hline Students Results & \multicolumn{2}{|r|}{171043262414605} & Semester & $16 / 07 / 2012$ & 6 & & 15 & & 0 & 6 & $\nabla$ & $\square$ & \multicolumn{2}{|c|}{ View Answer } \\
\hline Degrees Management & \multicolumn{2}{|r|}{171047484826113} & Quiz & $16 / 07 / 2012$ & 5 & & 10 & & 0 & 5 & $\nabla$ & $\square$ & \multicolumn{2}{|c|}{ View Answer } \\
\hline Valuation Management & \multicolumn{2}{|r|}{171053392474011} & Semester & $16 / 07 / 2012$ & 8 & & 15 & & 0 & 8 & $\nabla$ & $\square$ & \multicolumn{2}{|c|}{ View Answer } \\
\hline 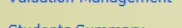 & \multicolumn{2}{|r|}{171061333178193} & Semester & $16 / 07 / 2012$ & 8 & & 15 & & 0 & 8 & $\nabla$ & $\square$ & & w Answer \\
\hline Students Summary & & 171871276778109 & Final & $17 / 07 / 2012$ & 19 & & 40 & & 0 & 19 & $\nabla$ & $\square$ & & w Answer \\
\hline Directory Manager & & 173157297658031 & Practical & $19 / 07 / 2012$ & 0 & & 0 & & 2 & 2 & $\square$ & $\square$ & & w Answer \\
\hline Course Reports & & 173166321278885 & Test & $19 / 07 / 2012$ & 4 & & 10 & & 0 & 4 & $\nabla$ & $\square$ & & W Answer \\
\hline Course Management & & 177244899218578 & Valuation & $24 / 07 / 2012$ & 3 & & 5 & & 0 & 3 & $\nabla$ & $\square$ & & w Answer \\
\hline Archive Management & & 177251417431398 & Valuation & $24 / 07 / 2012$ & 3 & & 5 & & 0 & 3 & $\nabla$ & $\square$ & & w Answer \\
\hline & & 183186285418850 & Quiz & $31 / 07 / 2012$ & 0 & & 10 & & 0 & 0 & $\square$ & $\square$ & & w Answer \\
\hline & & 190542285857810 & Valuation & 08/08/2012 & 3 & & 5 & & 0 & 3 & $\nabla$ & $\square$ & & w Answer \\
\hline & $\Phi$ & Edit Delete & & $17 / 08 / 2012$ & 0 & & 0 & & 0 & 0 & ) & 0 & & 0 \\
\hline
\end{tabular}

Figure 20: Teacher's Archive Management Sub-Module

\subsubsection{Student's Course Material Sub-Module}

This is the basic sub-module where students can view and download course lectures and references as shown in Figure 21.

\begin{tabular}{|c|c|c|}
\hline $\begin{array}{l}\text { Course Materials } \\
\text { Today Lecture }\end{array}$ & \multicolumn{2}{|r|}{$\begin{array}{l}\text { Download course lectures \& references } \\
\text { Or Double click to view online }\end{array}$} \\
\hline \multirow{2}{*}{$\begin{array}{l}\text { Today Lecture } \\
\text { Video Leectures } \\
\text { Teacher Messages } \\
\text { Examination } \\
\text { Results } \\
\text { Feedback }\end{array}$} & ऽ & \\
\hline & $\begin{array}{l}\square \text { CourseMaterials } \\
\begin{array}{|l}\square \text { 01-Super position } \\
-\square 02 \text {-Thevenins Theorem } \\
-\square 03 \text {-Nortons Theorem } \\
-\square 04 \text { 04-MaxPowerTransfer } \\
\square \text { References }\end{array}\end{array}$ & L1_Introducti... \\
\hline
\end{tabular}

Figure 21: Student's Course Materials Sub-Module

\subsubsection{Student's Today Lecture Sub-Module}

This sub-module allows students to follow teachers online as they deliver a lecture. Available also to students are the instructional materials and the theoretical considerations adopted by the teacher, as shown in Figure 22. 


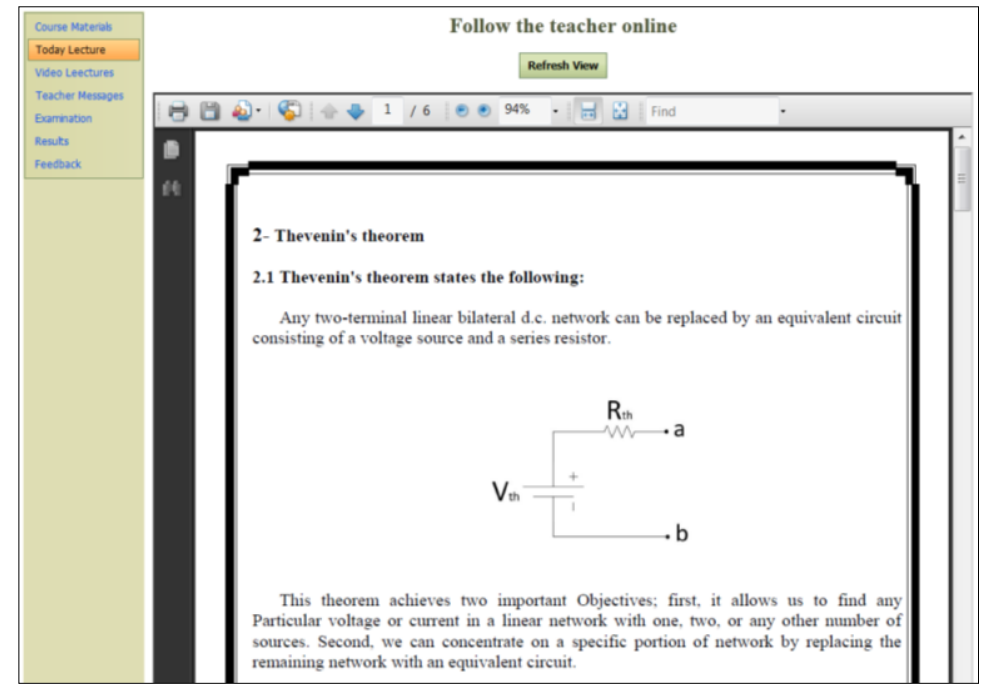

Figure 22: Student's Today Lecture Sub-Module

\subsubsection{Student's Video Lecture Sub-Module}

This sub-module provides students with access to archived video lectures as shown in Figure 23.

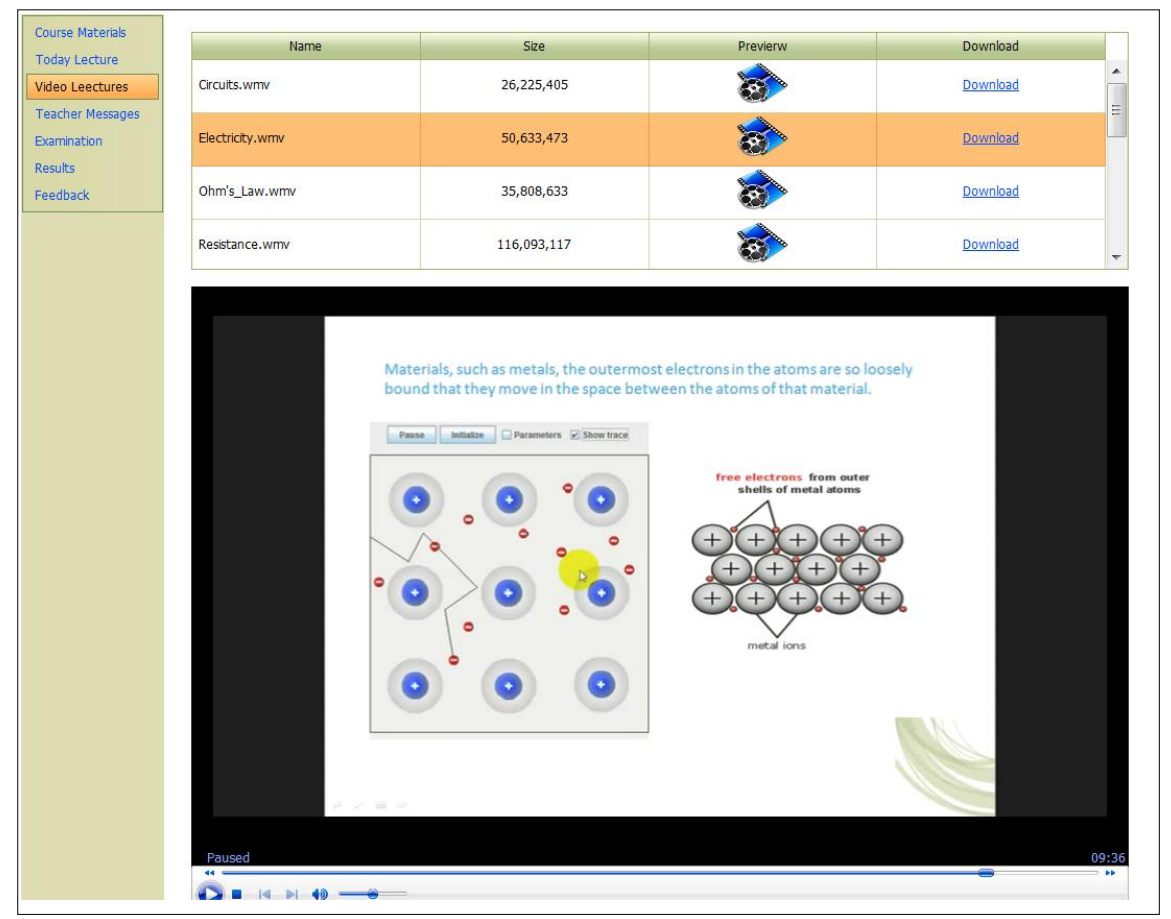

Figure 23: Student's Video Lecture Sub-Module

\subsubsection{Student's Teacher Message Sub-Module}

Through this sub-module, students receive instant messages from teachers. Shown in Figure 24 is the message "don't come late to the lecture" in the Arabic language. 


\begin{tabular}{|c|c|}
\hline Course Materials & Your teacher message is \\
\hline Today Lecture & لا تحتَأخر عن المفحاضرة \\
\hline Video Leectures & \\
\hline Teacher Messages & \\
\hline Examination & \\
\hline Results & \\
\hline Feedback & \\
\hline
\end{tabular}

Figure 24: Student's Teacher Message Sub-Module

\subsubsection{Student's Teacher Feedback Sub-Module}

This module allows students to send feedback messages that do not exceed 500 characters to their teachers, such as queries on lectures, or responses to teacher questions, as shown in Figure 25.

\begin{tabular}{|c|c|c|}
\hline Course Materials & New feedback & My Feedbacks \\
\hline $\begin{array}{l}\text { Today Lecture } \\
\text { Video Leectures }\end{array}$ & & Write your feedback below (max of 500 letter), and click send \\
\hline Teacher Messages & & \\
\hline Examination & & \\
\hline Results & & \\
\hline Feedback & & \\
\hline
\end{tabular}

Figure 25: Student's Teacher Feedback Sub-Module

\subsubsection{Student's Examinations Sub-Module}

Through this sub-module students can take online examinations. Constantly displayed is the exam's timetable that includes: exam time, current time, elapsed time, and remaining time, as shown in Figure 26. The time limit depends on the nature of the test. Some tests may have an unlimited amount of time, while others are timed as a matter of practice, just as they would be if administered on paper in a classroom. Special arrangements for students with accommodations can also be made to extend the time.

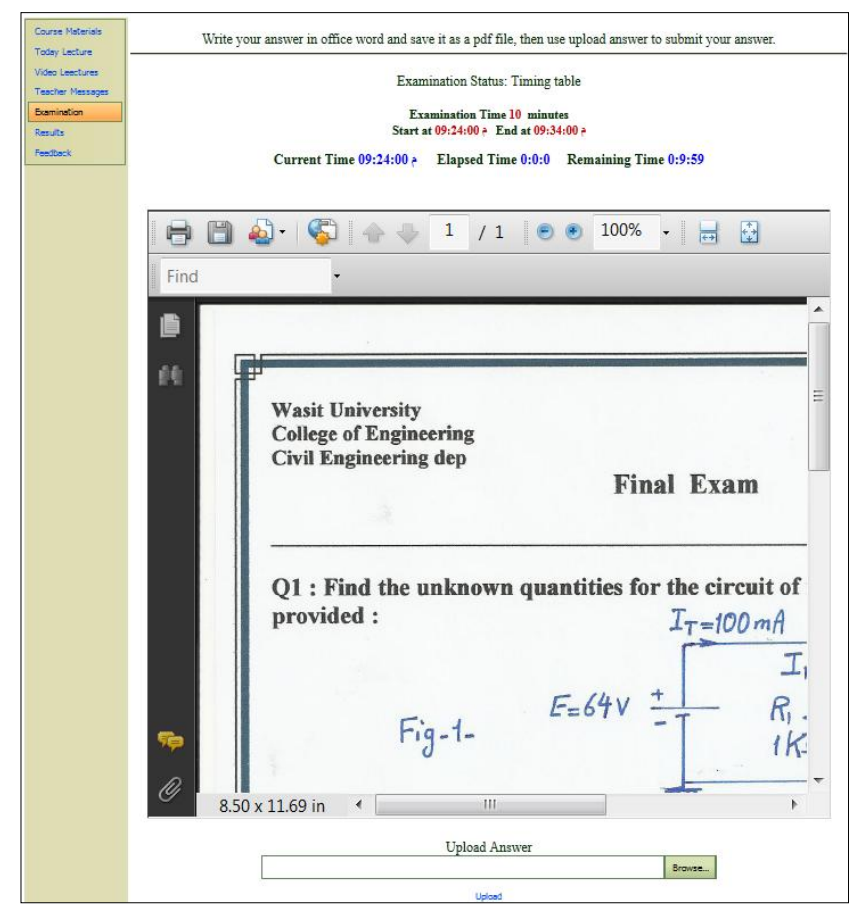

Figure 26: Student's Examinations Sub-Module 


\subsubsection{Student's Results Sub-Module}

The student's results sub-module has two options: "view results," shown in Figure 27, and "print results," shown in Figure 28. The view results sub-module allows students to know their grades on any examination previously taken by viewing detailed information that includes: the date, type, and score of the exam, the points added through curving, the grade as a percentage, and the final course grade as a percentage. The word degree used in the software refers to what is commonly known as grade. On the other hand, the print results sub-module offers students the ability to print these data for archiving purposes or other use.

\begin{tabular}{|c|c|c|c|c|c|c|c|c|}
\hline \multirow{4}{*}{$\begin{array}{l}\text { Course Materials } \\
\text { Today Lecture } \\
\text { Video Leectures } \\
\text { Teacher Messages } \\
\text { Examination }\end{array}$} & & & & View Results & \multicolumn{4}{|c|}{ Print Results } \\
\hline & \multicolumn{8}{|c|}{ Examinations Results } \\
\hline & Answer Date \& Time & Score & From Max & Curve + & Total & Degree per \% & Exam Type & Result \\
\hline & ص ص 09:06 20/10/2011 & 5 & 10 & 2 & 7 & $70 \%$ & Quiz & View result \\
\hline Results & ص 10:06 11/11/2011 & 8 & 10 & 0 & 8 & $80 \%$ & Quiz & View result \\
\hline \multirow{9}{*}{ Feedback } & ص ص 08:06 15/12/2011 & 4 & 10 & 2.3 & 6.3 & $63 \%$ & Quiz & View result \\
\hline & ص ص 21/01/2012 09:00 & 14 & 20 & 2.7 & 16.7 & $84 \%$ & Semester & View result \\
\hline & ص ص 02/03/2012 09:32 & 8 & 10 & 0 & 8 & $80 \%$ & Quiz & View result \\
\hline & ص ص 10:32 14/03/2012 & 3 & 10 & 7 & 10 & $100 \%$ & Quiz & $\underline{\text { View result }}$ \\
\hline & ص ص 10:32 08/04/2012 & 8 & 10 & 0 & 8 & $80 \%$ & Quiz & View result \\
\hline & ص ص 09:32 ص 12/05/2012 & 10 & 20 & 0 & 10 & $50 \%$ & Semester & View result \\
\hline & ص ص 12:32 24/05/2012 & 8 & 10 & 0 & 8 & $80 \%$ & Valuation & $\underline{\text { View result }}$ \\
\hline & ص ص 24/06/2012 09:00 & 23 & 40 & 0 & 23 & $58 \%$ & Final & View result \\
\hline & & & & & & Final score $=65.58$ & & \\
\hline
\end{tabular}

Figure 27: Students' View Results Sub-Module

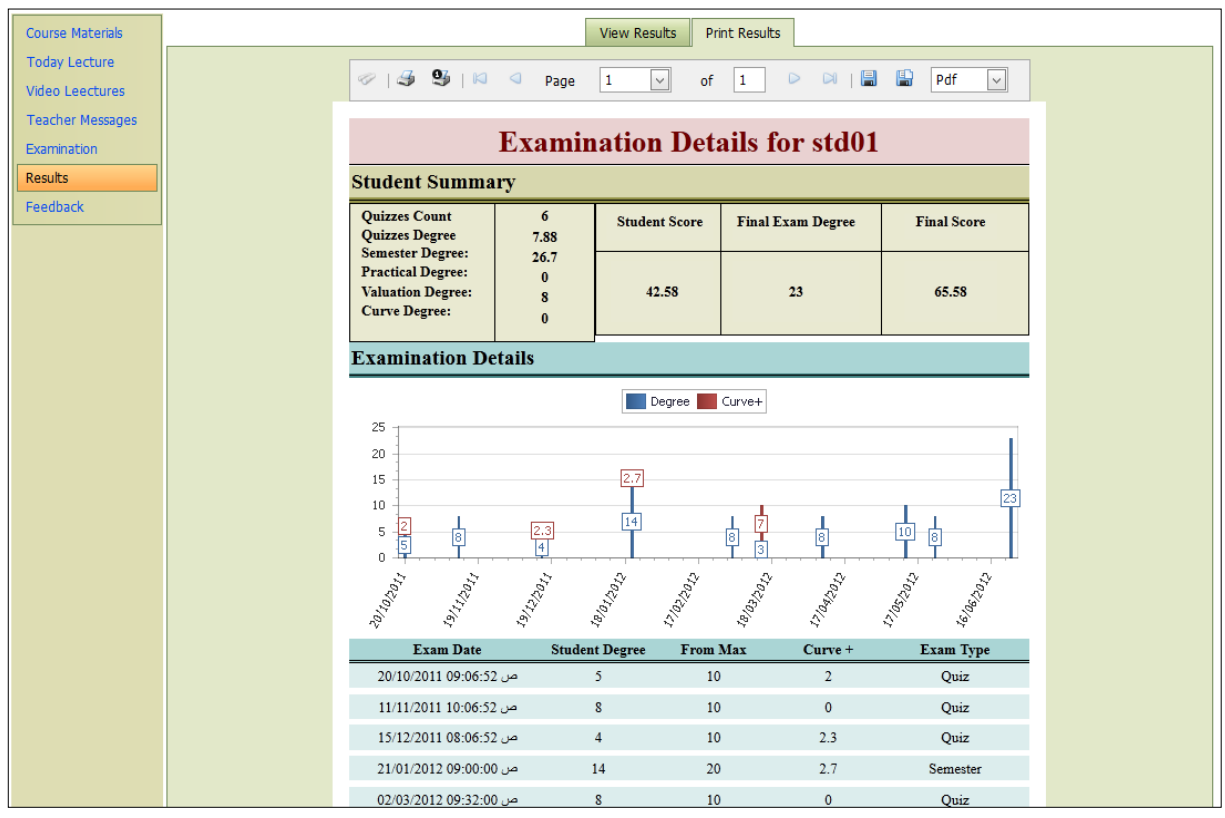

Figure 28: Student's Print Results Sub-Module

\subsubsection{Administrator Module}

This module is used by the administrator of the server to manage the whole system, as well as to update the system information with high flexibility. Course management options include adding and deleting courses, teachers, and students, and providing course material backup. 


\subsection{Middle Layer}

The middle layer represents an effective communication layer between the user's interface layer and the server layer. This layer uses Java Script web browser programming language and Microsoft Silver light web browser plug-in. One of its features is its ability to handle certain requests from the user's interface layer and return the response without having to send it to the server, which reduces substantially network traffic and server load. Various applications are handled by this layer, such as time monitoring for examinations, information and attention messages, downloading and uploading processes, video streaming and displaying, and reports displaying and printing.

\subsection{Server Layer}

This layer represents the core of the system and handles the communication between web server users and the database that stores all users' information, data files, and course management information such as previously closed courses, deleted students, and current opened courses.

The server layer was designed using Microsoft ASP.NET and structured query language (SQL) servers, which are known to have high performance and reliability in web server applications.

\section{CONCLUSION}

E-learning is the new trend in education. It is used by innumerable educational, industrial, and continuing education organizations worldwide. Among the many advantages of e-learning is the reduction of time and money devoted to the education enterprise. Ongoing research to strengthen this approach to education and to widen its implementation is of vital importance.

In this paper an integral e-system that performs and manages a complete educational process that can be used by any educational organization in a highly flexible, reliable, and secure manner as been presented. When tested, the system proved efficient for both parties: management and user. Our short-term goal is to implement this e-learning system at Wasit University in Wasit, Iraq, while the long-term goal is to expand the use of this or similar systems to all institutions of learning in Iraq.

\section{AUTHOR INFORMATION}

Dr. Hasan F. Khazaal, Electrical Engineering and Wireless Networking lecturer, serves as Associate Dean of the College of Engineering at Wasit University. He is licensed in electrical engineering and in educational technology and curriculum in Iraq. Dr. Hasan worked as head engineer at the ministry of industry for more than 23 years. He has an experience in tuning of Radar Antennae, Microwave Circuits, and Wireless Ad-hoc Networks. He has several publications in the field of Electrical Engineering and Communications. E-mail: hf1964@yahoo.com

Riyadh A. Abbas has a Master degree in electrical engineering and serves as the Associate Manager of Ibn Sina ELearning Center in Wasit University. He serves as the IT Manager in the Engineering College at Wasit University. $\mathrm{He}$ is a licensed engineer in the Iraqi Engineering Union. He spearheaded the development of the E-Governance System in the Engineering College at Wasit University. E-mail: riyadhabed@ yahoo.com

Basim M. Abdulridha, Electrical Engineering assist lecturer (M.Sc degree), serves as head of the committee of quality insurance of the department of Electrical Engineering, College of Engineering, Wasit University. He is licensed in Electrical Engineering in Iraq. He is qualified as a lecturer to teach in Technical Institutes in Iraq. Mr. Basim serves as a lecturer in the Electronic Training Institute, Baghdad. He has published two books in Electrical Circuits Analysis. E-mail: abdulridha56@yahoo.com

Mark Karam is an Associate Professor of Electrical Engineering at Tuskegee University. His research areas of expertise are in control systems, signal processing, artificial intelligence, and simulation. Dr. Karam has published many refereed articles and delivered many national and international presentations. He is a member of IEEE and the 
Alabama Academy of Sciences. Dr. Karam obtained his PhD in Electrical Engineering from Oakland University, Rochester, Michigan. E-mail: karam@mytu.tuskegee.edu

Dr. Heshmat Aglan, a professor of Mechanical Engineering, serves as the Associate Dean of the College of Engineering at Tuskegee University. He is a licensed engineer in the States of Alabama and Ohio. He spearheaded the development of Mechanical Dissection, a course for engineering students, as a part of the NSF Synthesis Coalition. Dr. Aglan has served on the Board of Directors for the Alabama Math Science and Technology Education Coalition (AMSTEC) since its inception. During the last five years, he has directed grants totaling over four million dollars in funding. He has more than 120 refereed publications. E-mail: aglanh@ mytu.tuskegee.edu (Corresponding author)

\section{REFERENCES}

1. Cheung, K. S., Lam, J., Lau, N., \& Shim, C. (2010). Instructional design practices for blended learning. IEEE Proceedings of International Conference on Computational Intelligence and Software Engineering (CiSE), Wuhan, China, 1-4.

2. Jie, C. (2010). Evaluation and modeling of online course using fuzzy AHP. IEEE Proceedings of International Conference on Computer and Information Application (ICCIA), Tianjin, China, 232-235.

3. Murillo, L. F. L., \& Velázquez, F. J. L. (2008). E-learning as a key aspect for the future of higher education. IEEE Proceedings of 19th International Workshop on Database and Expert Systems Application (DEXA), Turin, Italy, 431-435.

4. Pecheanu, E., Segal, C., \& Dumitriu, L. (2011). On modeling adaptive Web-based instructional systems. IEEE Proceeding of Global Engineering Education Conference (EDUCON), Amman, Jordan, 1146-1151.

5. Puvac'a, M., Roso, D., \& Zdrilic, I. (2010). Challenges and opportunities of introducing e-learning system. IEEE proceedings of the $33^{\text {rd }}$ International Convention (MIPRO 2010), Opatija, Croatia, 1074-1079.

6. Soreanuand, P., \& Saucan, E. (2003). Semi-continuous monitoring of student feedback in interactive synchronous e-learning environments. IEEE Proceedings of the 3rd International Conference on Advanced Learning Technologies, Athens, Greece, 276-277.

7. Squires, A., \& Cloutier, R. (2011). Applying a robust design approach to improve online systems engineering education. IEEE Proceeding of International System Conference (SysCon), Montreal, Canada, 371-378.

8. Xin, M. (2009). Design of a flexible e-learning system for employee's education in manufacturing industry based on knowledge management. IEEE Proceedings of International Symposium on IT in Medicine \& Education (ITIME), Jinan, China, Vol. 1, 1034-1038.

9. Zhang, C., \& Wang, F. (2010). E-learning instructional platforms based on network and multimedia technology. IEEE Proceeding of Second International Workshop on Education Technology and Computer Science (ETCS), Wuhon, China, Vol. 2, 464-467. 
NOTES 